\title{
Sustainable Methods of Funding Health Care in Primary and Secondary Care for the Elderly
}

\author{
Anwar Khan ${ }^{\mathrm{a}}$
}

\begin{abstract}
Clinical commissioning is a current health care management model for primary, secondary, and long term health care needs n United Kingdom nowadays. Form on 1 April 2013, Primary care trusts (PCTs) and strategic health authorities (SHAs) have been abolished. Clinical Commissioning Groups (CCGs) work with local authorities to address the wider determinants of health that is used to help people make positive changes to their lifestyle. NHS England (formerly the NHS Commissioning Board) and CCGs are currently responsible for commissioning the wide majority of NHS services. Local authorities take place on new public health commissioning responsibilities. England's 211 CCGs will take over from 303 PCTs. CCGs are responsible for $£ 65 \mathrm{bn}$ of the $£ 95 \mathrm{bn}$ NHS commissioning budget. CCGs are planning and commissioning hospital care, community care as well as elderly care and mental health services. All GP practices have to be members of a CCG, and every CCG board will include at least one hospital doctor, nurse and member of the public. This process has continuing healthcare funding for managing elderly care, but personal health budgets also needed for providing huge benefits for these individuals. The aim of CCGs in managing a health budget is to provide elderly people more choice and control over the money spent on meeting their health care and well-being needs. That is, clinical commissioning groups select services that meet the elderly people's needs in a flexibly and appropriately.
\end{abstract}

Keywords: Clinical Commissioning Groups (CCGs) $\bullet$ Elderly $\bullet$ Health Budget $\bullet$ Cost Control $\bullet$ Health Care Service Management

a Anwar Khan, MD., London Deanery Honorary Professor of Medical Education, Stewart House, 32 Russell Square, London WC1B 5DN, UK

Research areas: Management; Primary health care; Clinical commissioning groups; Cost control

Email: anwar.khan@nhs.net 
Primary health care services are spending nowadays significant amount of time providing health care for older people. Initiatives that support funding, sustainability, and integration of care for older people with complex health needs and social care with public and private providers are important for continuity and quality of care (Davies et al., 2011). The proportion of people aged 65 years and older is projected to grow from just under $15 \%$ (in 2000) to $23.5 \%$ by 2030 , while the proportion of those aged 80 years and over is expected to more than double (from $3 \%$ in 2000 to $6.4 \%$ in 2030) in Europe. There is a considerable difference between countries. Turkey and Ireland have the lowest proportion of people over 65 years of age (respectively 6 and 11\%), However, Germany and Italy have the highest proportion (approximately 20\%). In all countries these percentages are higher for females than for males and they are increasing. The funding of all health care system must be sustainable with the idea of "who pays" than "how much" we pay. Another important question is "Will healthcare be there with someone when he / she need it."

The funding of a health care system may be monopolistic, oligopolistic, or capitalist on a competitive basis. The financial intermediary is governmental in a monopolistic health system. A monopoly is exclusive control of the market by one business (government-run system) because there is no other group selling the product or offering the health service (Social Care Institute for Excellence, 2012). A true health care services monopoly rarely exists because if there is no competition, the health care business will increase the price while reducing output to increase profits. It can also lead to inferior health care services. An oligopolistic health care system is the middle between monopoly and capitalism (Wagner, 1988). An oligopoly is a small group of health care businesses that control the health care market for a certain health care service (e.g., out-patient and hemodialysis).

Capitalism in the health care market is a condition wherein there is open competition, a free health care market, and private ownership of all hospitals and providers, such as family practice centers (Gage et al., 2012). This encourages private businesses and investments through the dictates of supply and demand, price, and distribution, which are controlled by the health care business owner's investors and customer. Profits are distributed among the owner's shareholders and customers that are the shareholders in private companies called capitalists (Care Quality Commission, 2012). 


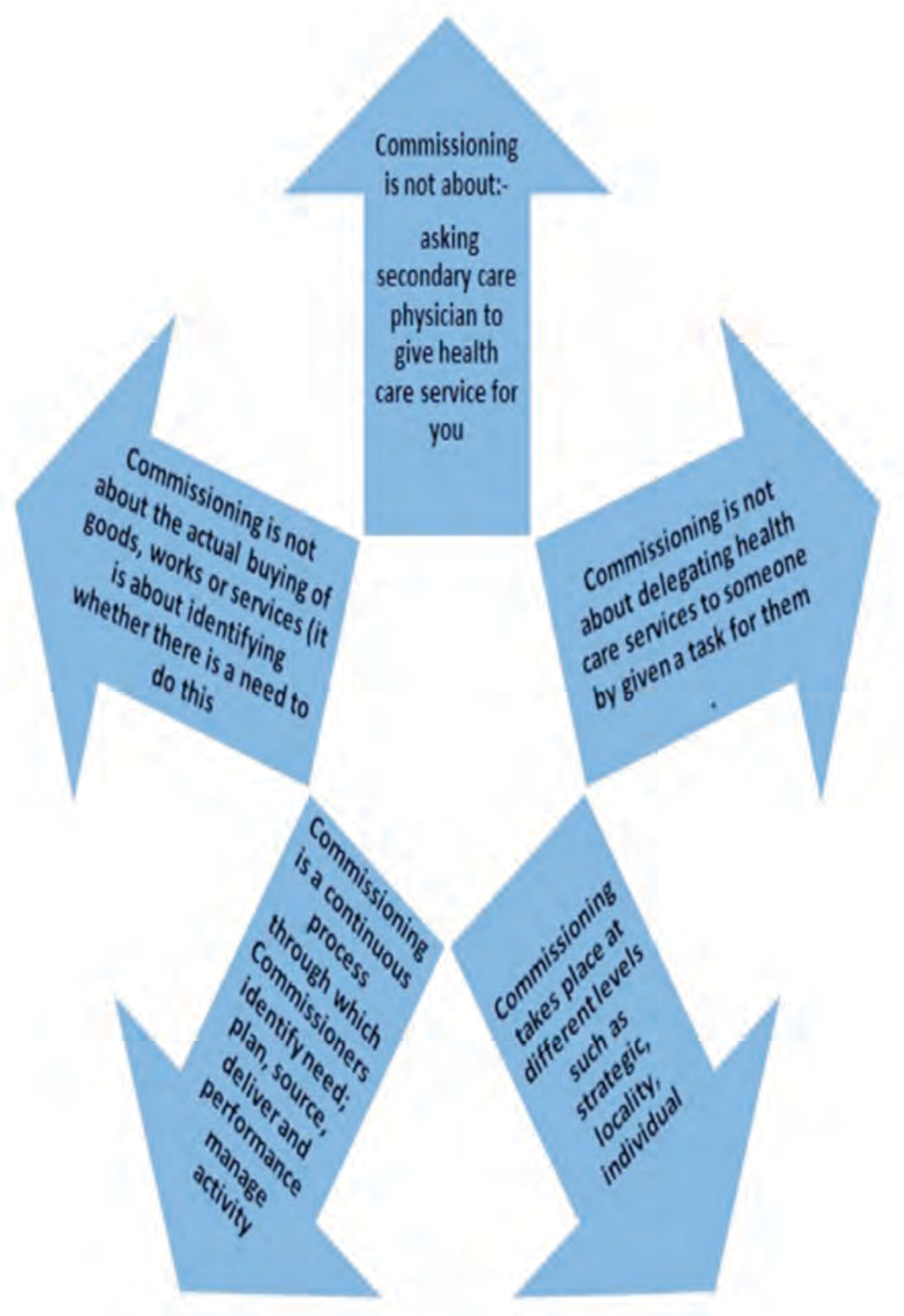

Figure 1: What is commissioning is and is not.

For the sustainability of monopolistic funding approaches, one of the easy ways for funding health care is by commissioning services to see individuals as eligible recipients of health care services provided from a limited range 
of options as identified by health professionals (NHS England, 2012). This strategy sees individuals as local citizens, with a full health rights, choices, and responsibilities. The role of community health and social care can then be focused on supporting people with the most complex needs who require added specialized and tailored health care services (British Geriatrics Society, 2011).

Commissioning is a complex process of business that helps to address a local population need such as the elderly. This process has several outcomes and is a sustainable way to provide health care (Thames Valley Health Innovation and Education Cluster, 2013). This is a well-planned and managed approach for systems and equipment for a safe and functional environment that meets established design requirements and stakeholder expectations. Using commissioning activities will facilitate understanding needs, analyzing capacity, and monitoring health services. This is the way of assessing the needs of a local population in the city and establishing health services to meet those needs.

This way helps to construct many products and services to local population such as children, the elderly, women, etc. In health care services, health commissioning is not easy to use; however, it is supposed to be a unique way to cut costs in United Kingdom nowadays. CCGs are in use in order to manage health care services. CCGs are made up physicians, nurses, allied health care professionals (Gordon et al., 2013).

CCGs use their knowledge of local health needs to plan and buy services for their family practice center from any health care service provider that meets Health Budget Law and formal health insurance schemes of their country. 12 CCGs across England where clinically-led initiatives have both improved the quality of healthcare services for patients and saved money (Clinical Commissioning in Action 2012). Figure 1 describes the commissioning process.

The Department of Health describes commissioning as the means to secure the best value for local citizens of a city and taxpayers (Seymour \& Froggatt, 2009). This is the process of facilitating the health care need by specifying and procuring services for the local populations of big cities. Delivering the best possible health and well-being outcomes and providing the best possible health and social care provision within the best use of available resource needs levels of strategy (National Council for Palliative Care and NHS, 2007). 
Those levels are shown in Figure 2:

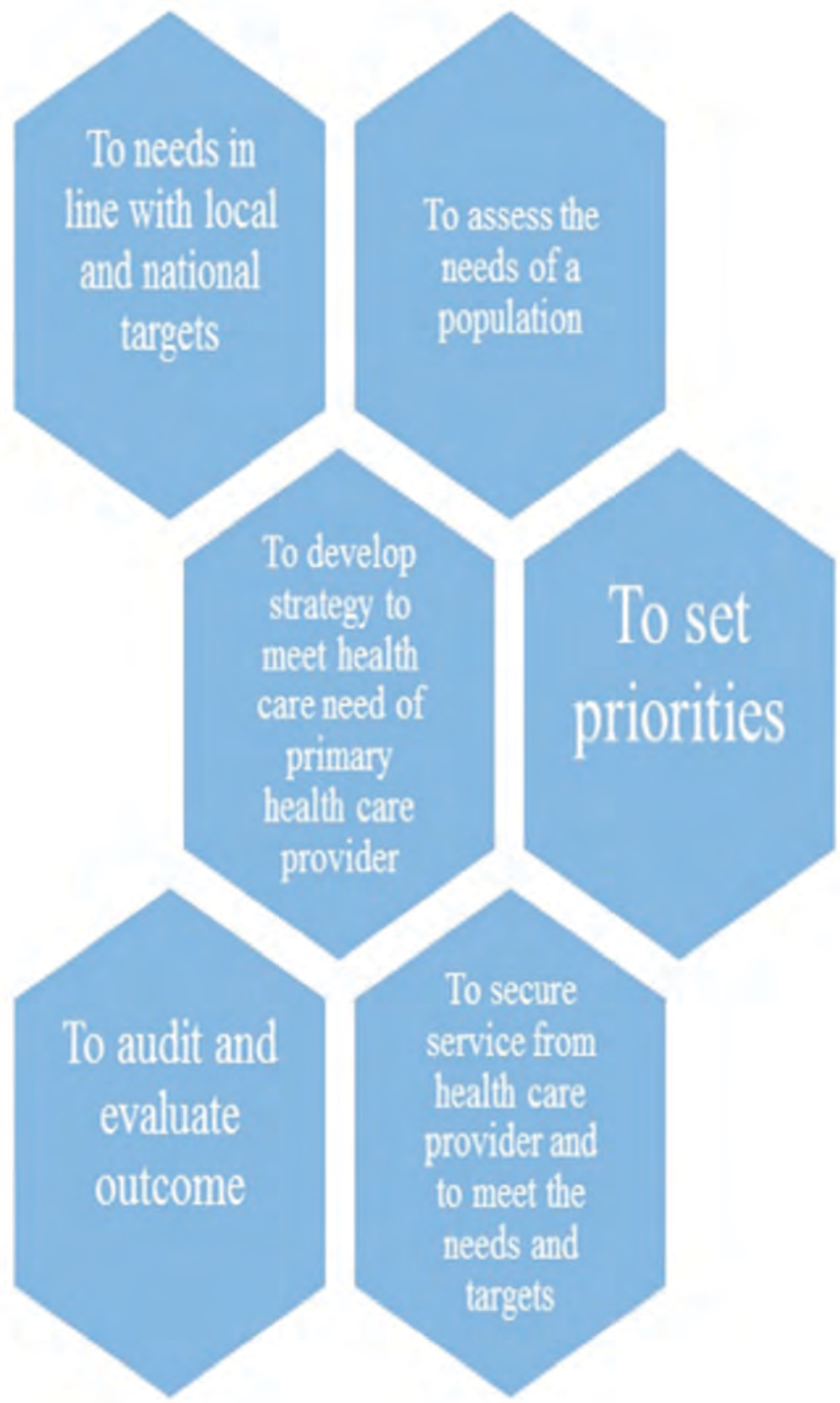

Figure 2: Commissioning levels. 
Commissioning for the elderly has become established over the past decade through a number of papers emerging from the government, which have set out the aims for service delivery and defined approaches to commissioning services. A timeline is provided on this site providing an outline of the key documents, which describe and define commissioning (The Health Foundation, 2011).

The principal idea is to achieve those outcomes and supporting health services providers to enable them to deliver outcomes for elderly individual health service users. Health care commissioning can happen at many levels, either in primary care or in secondary care by supporting elderly as shown in Figure 3.

\section{Support People by Health Commissioning}

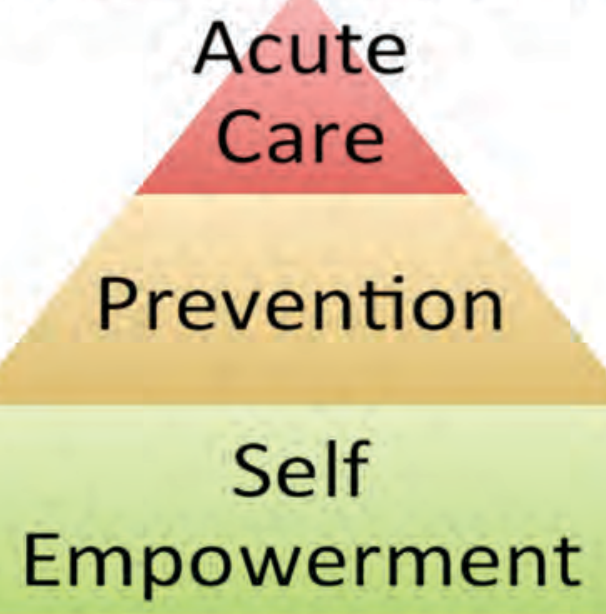

Figure 3: Strategy in supporting health.

The strategy of health care commissioning can work if people use this process with the local authorities. These processes are shown in Figure 3.

The CCGs has made caring for the elderly a key priority and will create its "Integrated Older People's Pathway and Adult Community Services Procurement" process to secure a contract that will offer joined up, integrated care across geographic and organizational boundaries. Specific strategies for older people via health commissioning are shown in Figure 4. 


\section{Support of People For Health Commissioning}

\section{Self Care}

\section{Promoting Health Care}

Acute

Care

- Ode people shoud have

cloce, and corto ove

sevicas tioned to met the?

insidal reats.

- Oter peope should of

as independent as

portibe for as ong ar

possbe.

Oder peope showd

be beathy and wel

abe to make a

postive

cortibution, and

abe to actest

mansteam

'evertaj' serices.

Figure 4: Community elderly care services by CCGs. 


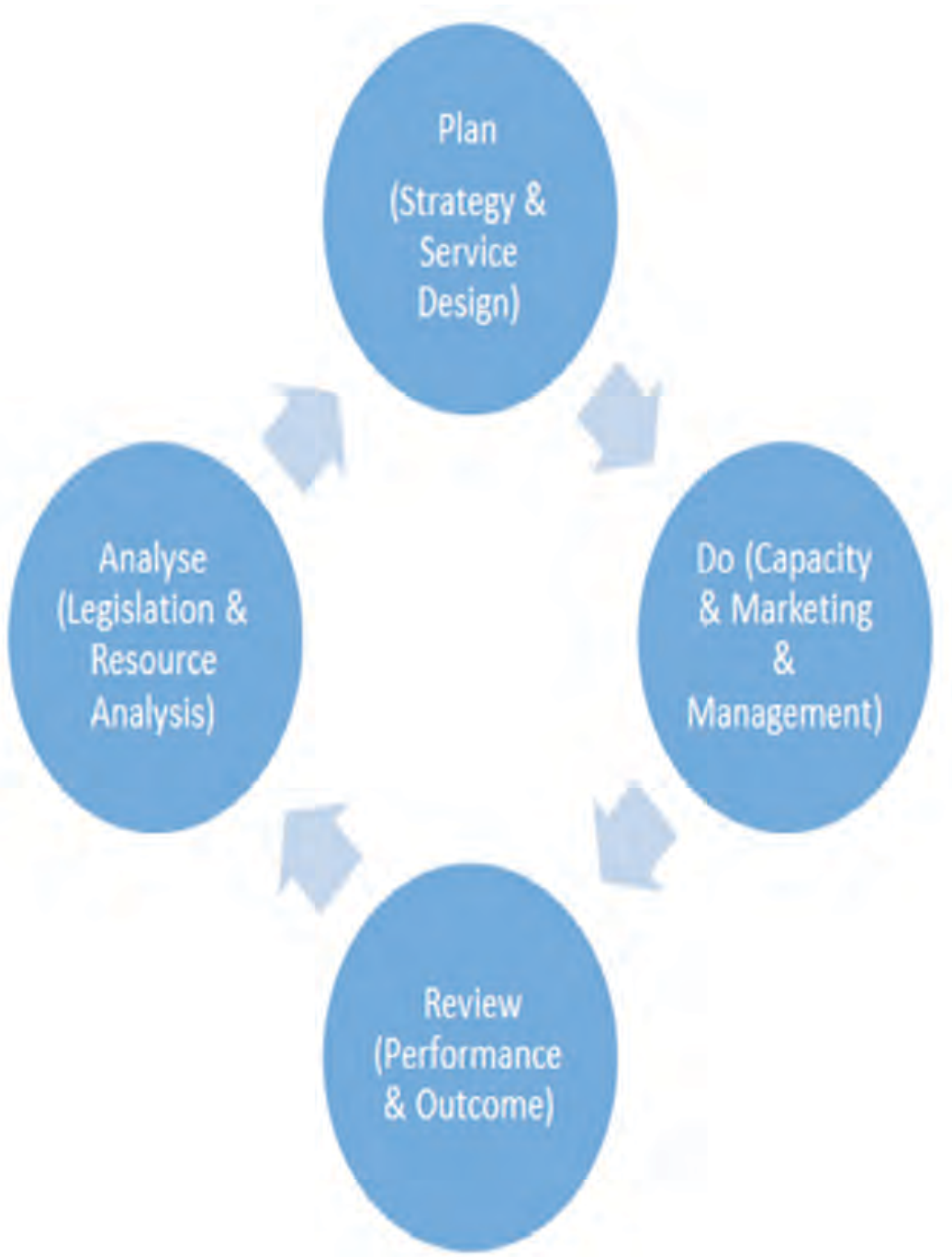

Figure 5: The commissioning cycle, which should in turn inform the ongoing development of strategic commissioning.

CCGs and integrated health care usually means that providers collaborate on primary and secondary care. In practical terms, this result means fewer hospital admissions, which is often beneficial both for the patient and the health care economic system as a whole (Centre for Policy on Aging, 2009).

There are many models of health commissioning activities; they usually describe a cyclical process of activities encompassing local population health care assessment needs, allocating resources to meet health care needs, developing or purchasing 
health care services, and monitoring health care performance via indicators (Social Care Institute for Excellence, 2013). This cyclical health care performance management elements are analyze, plan, do, and review (see Figure 5).

\section{Results}

Commissioning for the elderly is not buying health services from secondary care hospitals, physiotherapies, dietetics, etc. It means that health services are procured at the best possible cost to meet the needs of the purchasers and health care seekers in terms of quality and quantity, time, and location with the collaboration of both of them. "Purchasing and Contracting" equally apply to in-house service provision for elderly or grant funding arrangements as the same time.

The commissioning cycle can be broken down into four stages:

Step one: analyze and plan

Step two: design pathways

Step three: specify and procure

Step four: deliver and improve

Improving health services for elderly people is CCG's priorities. The aim of CCGs for elderly is to deliver improved patient experience, better community care, and reduced unplanned admissions to hospital in a safe way. The CCG's overall vision is for sustainable health service transformation for elderly is "manage locally by primary care clinicians in partnership with their local community, commissioning quality health services for elderly that ensure value for money and the best possible outcomes for old people who use them."

Elderly people will be managed therefore by CCGs with the aim of providing whatever is needed to prevent them needing acute care or long-term residential care, or unnecessary dependence on the health and social care system. 


\section{References}

British Geriatrics Society. (2011). Quest for quality: Delivering healthy ambitions better for less: Care homes enhanced medical service (NHS Yorkshire and the Humber, 5). Retrieved from http://www.bgs.org.uk/campaigns/carehomes/quest_quality_care_homes.pdf Care Quality Commission. (2012). Health care in care homes: A special review of the provision of health care to those in care homes. London: Author.

Centre for Policy on Aging. (2009). Ageism and age discrimination in mental health care in the United Kingdom. Retrieved from http://www.cpa.org.uk/information/reviews/ CPA-ageism_and_age_discrimination_in_mental_health_care-report.pdf

Davies, S. L., Goodman, C., Bunn, F., Victor, C., Dickinson, A., Iliffe, S. ... Froggatt, F. (2011). A systematic review of integrated working between care homes and health care services. BMC Health Services Research, 11, 320. doi:10.1186/1472-6963-11-320

Gage, H., Dickinson, A., Victor, C., Williams, P., Cheynel, J., Davies, S. L. ... Goodman, C. (2012). Integrated working between residential care homes and primary care: A survey of care homes in England. BMC Geriatrics, 12, 71. doi:10.1186/1471-2318-12-71

Gordon, A., Franklin, M., Bradshaw, L., Logan, P., Elliot, R., \& Gladman, J. (2013). Health status of $U K$ care home residents: A cohort study. Age \& Aging. Advance online publication. doi:10.1093/ageing/aft077

National Council for Palliative Care and NHS. (2007). Building on firm foundations - improving end of life care in care homes: Examples of innovative practice (NHS End of Life Care Programme). London: DH.

NHS England. (2012). Securing excellence in commissioning primary care. Retrieved from http://www.england.nhs.uk/wp-content/uploads/2012/06/ex-comm-pc.pdf

Seymour, J., \& Froggatt, K. (2009). End of life care in care homes: Understanding and mapping innovative solutions. Nottingham: University of Nottingham and Lancaster University.

Social Care Institute for Excellence. (2012). Effective supervision in social work and social care (Research Briefing 43). London: Author.

Social Care Institute for Excellence. (2013). Practice survey: Older people living in care homes access to and experience of GP services. London: Author.

Thames Valley Health Innovation and Education Cluster. (2013). Delivering an integrated GP and medicines management service for the residents of care homes. Retrieved from http:// www.tvhiec.org.uk/programmes/care-closer-to-home/integrated-care-homes/ 
The Health Foundation. (2011). Learning report - making care safer: Improving medication safety for people in care homes: Thoughts and experiences from carers and relatives. London: Author.

Wagner, G. (Chair). (1988). Residential care: A positive choice (Report of the Independent Review of Residential Care, Vol 1). London: HMSO. 